\title{
Effectiveness of Free Weight Exercise And Super Set Machine System on Strength and Muscle Hypertrophy
}

\author{
Hadi $^{1}$, Soegiyanto ${ }^{2}$, Setyo Rahayu ${ }^{3}$, Hari Setiono ${ }^{4}$ \\ 1,2,3 Graduate School Universitas Negeri Semarang Jl. Kelud Utara III Semarang 50237, Indonesia \\ ${ }^{4}$ University Negeri Surabaya, Faculty Science Sports UNESA Tongue Campus Wetan Surabaya, Indonesia \\ Corresponding email: hadi_jati_diri@yahoo.co.id
}

\begin{abstract}
Muscle hyperthropy is an indicator of muscle strength . Super set system as media in maximizing on weight training. Free burden is generally preferred over machines by athletes for strength training because they involve the incorporation of muscle mass and require greater stabilization. The use of free weights can allow one to gain more muscle mass and strength with regular training. The objective of the research was to know the effectiveness of free weight and machine training methods super sets, the strength and muscle hypertrophy. The experimental with factorial $2 \times 2$ was given a tire training program which was composed of maximum repetition (RM) $70 \%$ to $80 \%$ for 3 months. Fifteen lifter athletes were used on this study. The result was Group $x$ interaction time for strength with significance $(p=0.054)$ with the free weight training group experienced a greater strength increase compared to the machine weight training group (13.9\% -8.6\%). Thigh flexor thickness increased significantly by $3.9 \%$ and $5.1 \%$ in the group of machine groups and weight free groups, respectively ( $\mathrm{p}<0.01$ ), without differences between groups. There is a significant tendency for free-load groups for the maximum strength compared to the load-machine group. While hypertrophy there is no difference. The conclusion was free weight exercise more effective than super set machine system.
\end{abstract}

Keywords: free weight, hypertrophy, strength

\section{Introduction}

Weight training is an important part of every exercise program. This can be used to maintain or increase muscle hypertrophy, strength, power, and even endurance (McArdle et al., 1999). Weight training also has a positive effect on functional capacity, increase basal metabolic rate, lower blood pressure, and increase blood lipid profile, insulin sensitivity and glucose tolerance (Kraemer et al., 2002). In order to achieve one's fitness goals, the right training modalities need to be considered. One of the controversies is whether the use of a more traditional program that consists of free or a machine that is better for building muscle mass and strength. Shurley and colleagues (2017) stated that for several years there was a raging debate about free weight versus machines and dedicating a significant focus from their script to specific topics of free weight training and machine power, this critical analysis would challenge writers and researchers.

Resistance training is an integral component of the total conditioning program. Many studies have described many physiological adaptations for weight training (Hakkinen and Kallinen, 1998; Martyn-St James and Carroll, 2009; Tsolakis, Vagenas, and Dessypris, 2004). Examples of physiological adaptations that result from weight training are: increased size of muscle fibers and strength, increased capillary density, increased carbohydrate metabolism, increased tendon and ligament strength, increased body composition, and increased bone mineral density. The study also shows that consistent resistance training programs can improve athletic performance, have a positive psychological impact, and increase energy expenditure while reducing the risk of injury and some types of illness, and help in recovery from various complications (Pearson, Faigenbaum, Conley, \& Kraemer, 2000). Along Santos, et al. (2010: 314) which states that alternative weight training and agonist / antagonist training is carried out every day for 8 weeks, 3 sets, 10-12 reps per set, except for abdominal exercises which are 3 sets with 1520 reps, can increase strength and flexibility.

The purpose of the study was to analyze the effectiveness of free weight training and the super set machine system for the results of strength and hypertrophy of the muscles . The benefits of this study are to improve and develop the potential and mindset optimally from the results of weight training in the development of comprehensive training in the gym and sports achievements 


\section{Methods}

( $\pm 1 / 2-1$ page, 15 spacing)

This type of research uses experimental types. The research design used a pretestposttest design group. The variables in this study are free weight training and machine with super set systems. The population used in this study is a breeding center Athlete Program 2017 Java outstanding athlete man age 16-18 years. The sample used is those that have fulfilled the capability and conditions for inclusion and exclusion . Research using Desaint Matching. The sample was divided into two groups according to the ranking results of the leg muscle strength group by the ABBA method

Data collection instrument using muscle hyperterthy measured using . Extremity Girth, The steps taken in the measurement of the relaxed muscle state, facilitated by having subjects lying on their backs and stretching their uterus to around $35-45^{\circ}$ as measured by goniometer, and then resting leg weight on the heel. Steps for foot circumference are taken in the following:

Step 1 is midway between the proximal patella and the anterior superior iliac spine (ASIS), measured in centimeters

Step 2 is one-half of the distance between the proximal knee and site 1

As for the strength of leg muscles using $1 \mathrm{RM}$ squats . Data analysis techniques using ANOVA continued with the determinant test using SPSS 16 .

\section{Results and Discussion}

The data used to analyze the research data were muscle hyperterthropy consisting of thigh muscle hypererthropy in athletes at the 2017 Central Java high achieving athlete breeding center before and after being given the super weight training set in the group free wight experiment 1 and the machine in experiment group 2.

All values were means $\pm \mathrm{SD} *$ Main effects were significant $\operatorname{sex}(\mathrm{p}<0.05) * *$ significant time main effect $(\mathrm{p}<0.01)$

Based on the table above shows the test results between pretest and posttest treatment in this study. Comparison of the ability of the athlete before treatment with the ability of the athlete after treatment to find out the presence of interactions. Variables that have a $p$ value of $<0.05$ means that there is an interaction of the weight training program set of super set free weight systems and machines against strength, hypererthropy, muscle in athletes in the 2017 Central Java high achievers athletes breeding center program. Group x interaction time for strength with significance $(\mathrm{p}=0.054)$ with the free weight training group experienced a greater strength increase compared to the machine weight training group $(13.9 \%$ vs $8.6 \%$ ). Thigh flexor thickness increased significantly by $3.9 \%$ and $5.1 \%$ in the group of machine groups and weight free groups, respectively ( $p<0.01$ ), without differences between groups. There is a significant tendency for free- load groups to have maximum strength compared to machine-load groups. while hypererthropy no there is difference

Table 1. Data on pre-test and post-test for muscle strength and hypererthropy

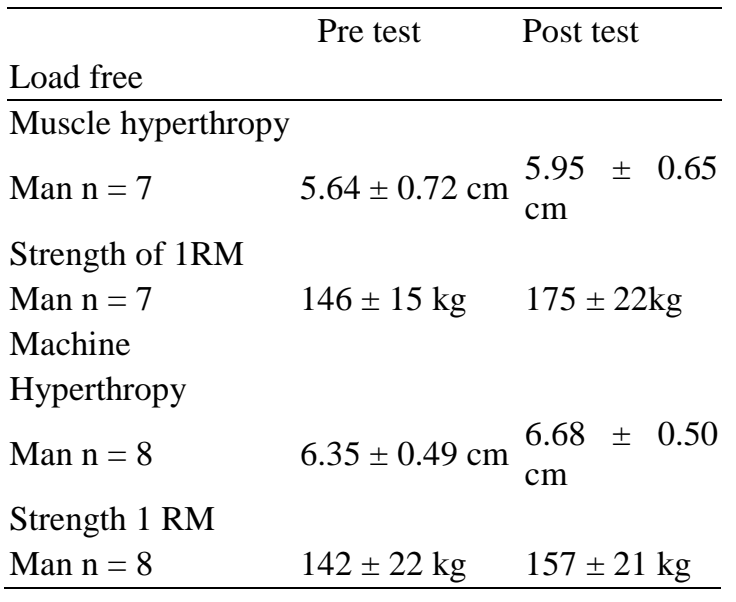

Muscle strength testing is carried out pretreatment and post-treatment. The total volume (set, repetition and percent of 1RM) and cumulative remainder remain9 identical for both training groups during the study. This finding supports the notion of specificity which refers to the concept that the greater the similarity that exercise has actual physical performance, the greater the probability of transfer (Chandler et al., 2008). Boyer (1990) also has the same results as strength training and specificity. In this study exercise samples used leg press exercises. Machines experience a greater advantage in strength when tested on their own devices. These results prove from the theory above that the results of the study showed a significant increase in strength occurred in the use of super set free loads.

These findings can be attributed to the fact Wirth and Partners (2016) p ulkan menyim 
squat exercise is more effective in improving kine fw leap. Good squat group nor leg significantly increased maximum isome-tric and dynamic strength (1RM), without significant differences between groups for these results.

When the group loads free Super sets do exercises 3 superset of squats and deadlifts, there are $2 \mathrm{~min} 30 \mathrm{sec}$ breaks between sets so the super set training group also has a 5 minute cumulative break per session. Recovery time of 3 to 5 minutes of exercise allows full recovery of muscle ATP formation and about 90\% regeneration of creatine phosphate (Hultman \& Sjöholm, 1986). There are still no provisions regarding the amount of rest time (menit 3 minutes) whether it is beneficial compared to shorter rest periods (menit 3 minutes) in increasing strength, but longer rest periods seem more appropriate when doing strenuous exercise or nearing maximum. Kay et al. (2000) showed that with almost no rest between muscle actions, there was a concomitant decrease in peak torque seen during the set of isokinetic-concentric exercises. The effect

the same may also be seen in this study although this study is not an isokinetic focus and has a simple resting time.

Judging by the general advantages of free weights including that they need balance and coordination such as actual sporting events, more variety of large muscle mass exercises can be done which can increase energy expenditure, and they can be used for ballistic training and explosions. Free weight training can place greater stress on the body due to greater activation of muscle mass. Therefore it is anticipated that free load training will increase cortisol production. Cortisol is a catabolic hormone released from the adrenal cortex in response to stress training.

Free weights proved efe ktif increase the mass ot ot and strength there are already a number of direct comparison between two forms of training. However, research has shown that training in an unstable environment ( load free ) results of increased muscle activity (McCaw et al., 1994; Behm et al., 2005; Schwanbeck et al, in Press.). Theoretically, this increase in muscle activation must result in increased release of testosterone (Kraemer et al., 2005), and this increase in testosterone must lead to a greater increase in muscle mass and strength (Herbst et al., 2004).

Increased ability to work muscles due to exercise caused by physiological changes that occur in the neuromuscular system ( system adaptation neuromuscular ). These changes include the occurrence of muscle hypertrophy (Suharjana, 2013: 18). According to Baechle and Groves cited by Suharjana (2013: 18), the addition of muscle size ( hypertrophy ) is often caused by the increase in muscle fibers that exist, fibers that have existed from birth. Increased muscle fibers due to the increase in protein actin and myosin. Several studies have shown hypertrophy can occur in only 4 to 6 weeks (Staron et al. 1991, 1994).

Two training sessions per week are conducted because it is recommended (Baechle \& Earle, 2000) that individuals train muscle groups 2 to 3 times per week with at least 24-48 hours of rest between training the same muscle group. Since the research used trained subjects, researchers want to ensure enough time for recovery and prevent injury from occurring

Based on data analysis, the results of the study showed that it was not there are differences muscle mass in exercise using free weights and machine super set method against thigh muscle hypertrophy in the Athlete Program 2017 Central Java achievers athletes center .

Super sets are terms used to describe changing-NATing two exercises for two different target muscle groups. Baechle \& Roger (2000) stated that the implementation of super set system training is a specific or specific form of weight training involving agonist and antagonist muscles to maintain muscle balance in stages and detail. Hypertrophy will occur in people who exercise with a load marked by an increase in white muscle (fast) about $45 \%$, when compared to lay people or sportsmen who need endurance.

It is important to recognize that free weights and most strength training machines are resistance - resistant exercises. The amount of mass lifted does not change throughout the range of motion using one of these forms of training. However, external torque receptions change throughout the range of motion

Free weight has an external particle arm that changes naturally and changes with a single combined exercise and several external 
arm movements that vary in several combined exercises. The Nau tilus engine uses an eccentrically engineered and mechanically designed pulley known as a variable cam on the external moment arm. Free weights and machines used or All selected uses mass to provide durability, which remains constant through the range of motion. And they all provide external torque, which varies throughout the range of motion.

Benefits in this elite pen are (1) learning and information for trainers that weight training with free weight super set system methods is very helpful in improving power and muscle hypertrophy , (2) the development of sports science, especially experimental research in the field of load latency for drip tighten up on Settings speed on when do exercise load, Implications of this study are expected to be able to implement a super set system weight training program on strength and Muscle hypertrophy for trainers at sports clubs so that they have an advanced impact on sports performance according to their abilities.

\section{Conclusion}

Free weight training super set systems are more effective than using exercises machine load on results power and hypertrophy muscle thigh

\section{References}

Bottinelli, R., Canepari, M., Reggiani, C., \& Stienen, G. (1994). Myofibrillar ATPase activity during isometric contraction and isomyosin single composition of skinned muscle fibers. The Journal of Physiology , 481 (Pt. 3) .663-675.

Burke, LM 2001. Branched-chain amino acids (BCAAs) and athletic performances International SportMed Journal 2, 1-7.

Baechle, TR \& Roger W.2000. Earle, Essential of Strength Training and Conditioning. Iowa: Human Kinetics

Beachle TR, and Earle RW. (2008). The Essentials of Training Strength and Conditioning . Baechle TR, Earle, RW, (Eds) . Champaign, IL: Human Kinetics.
Behm, DG, \& Anderson, KG (2005). Stem muscle activity increases with unstable squat movements. Canadian Journal of Applied Physiology, 30, 33-45.

Boyer BT. Comparison of the effects of the three strength trafficking programs on women. J Appl Sport Sci Res 1990; 4 (5): 88-94.

Chandler, J., \& Brown, L. (Eds). (2008). Airconditioning for human strength and performance. Baltimore, MD: Lippincott Williams \& Wilkins.

Häkkinen, K., Kallinen, M., Izquierdo, M., Jokelainen, K., Lassila, H., Mälkiä, E., et al. (1998). Changes in agonistantagonist EMG, muscle CSA, and force during strength in middle-aged and older people training. Journal of Applied Physiology, 84 (4), 1341-1349.

Kraemer, WJ, Ratamess, NA, \& French, DN (2002). Resistance training for health and performance. Current Sports Medicine Reports, 1 (3), 165-171

Kraemer, WJ, \& Ratamess, NA (2005). Hormonal responses and adaptations for resistance training and training. Sports Medicine, 35, 339-361.

Martyn-St.James, M., \& Carroll, S. (2009). Strength training combined with plyometric jumps in adults: Sex differences in fat-bone axis adaptations. Journal of Applied Physiology , 107 (2), 636-637.

McArdle, WD, Katch, FI, Katch, VL (Eds.) (1999). Sport \& exercise nutrition. Baltimore, MD: Lippincott Williams \& Wilkins

Pearson, D., Faigenbaum, A., Conley, M., \& Kraemer, W. (2000). National Strength and Conditioning Association's Basic Guidelines for the Resistance Training of Athletes. Strength and Conditioning Journal , 22 , 14-27. 
Santos, E. et.al. (2010). Influence Of Moderately Intense StrengthTraining On Flexibility In SedentaryYoung Women. Journal Of Strength And Conditioning Research 2010 National Strength And Conditioning Association. 24 (11) / 3144-3149.

Staron , RS, Karapondo , DL, Kraemer, WJ, Fry, AC, Gordon, SE, Falkel , JE, et al. (1994). Skeletal muscle adaptations during early phase of heavy-resistance training in men and women. Journal of Applied Physiology , 76 (3), 1247-1255.

Staron, RS, Leonardi, M., Karapondo, D., Malicky, E., Falkel, J., Hagerman, F., et al. (1991). Strength and skeletal muscle adaptations in heavy-resistance-trained women after detraining and retraining.
Journal of Applied Physiology , 70 (2), 631-640.

Shurley JP, Todd JS, Todd TC. The science of strength: reflec- tions of the National Strength and Conditioning Association and the emergence of research-based strength and condi- tions. J Strength Cond Res 2017; 31 (2): 517-30.

Tsolakis, C., Vagenas, G., \& Dessypris, A. (2004). Strength adaptations and hormonal responses to resistance training and detraining in preadolescent laziness. Journal of Strength and Conditioning Research 18 (3), 625-629.

Wirth K, Hartman H, Sander A, et al. The impact of squat and leg press rear training on maximum strength and speed strength. J Str eng the Cond Res 2016; 30

(5):

1205-12. 